perience has proved; still no one would be so incredulous and false as to deny its general value as a medicine in cases of vomiting, \&c. Why we should wonder and marvel at the therapeutical effects of ten or twenty drops of pyro. acet. spirit, or naphtha, any more than at one drop of hydrocyanic acid, or creosote, I cannot imagine. I would recom. mend others to try the remedy and judge for themselves; and, in justice, I would urge them to try it early in the disease, and not to wait until they are satisfied of the existence of phthisis, when patients are too clcarly expectorating their lungs; or to waste valuable time in the hitherto lamentably unsuccessful routine of practice, and then adopt the waphtha treatment; such a plan of proceeding, $\vec{I}$ maintain, is not only unscientific but unfair; and to sceptics I would add, that until they have patiently and honestly so tested the powers of naphtha, their opinions must be valueless. Practitioners will discover, if they have not had introduced to their notice a new specific, that in a majority of cases of the earlier stages of consumption naphtha is a most valuable and powerful agent in checking the progress of this terrible disease.

I trust that the foregoing case and observations will be acceptable to the pages of your widely-circulated and independent Journal, which first announced Dr. Hastings' discovery of naphtha as a new therapeutic agent. I hasten to close my remarks with cautioning practitioners to be particular about the naphtha, as a matter of all importance. I have on two different occasions detected a harsh deleterious article being sold by druggists reputed for their good naphtha, whereby my patients suffered from severe vomiting and general disturbance, followed by a disgust for the medicine, which was with difficulty overcome. I am, Sir, your obedient servant,

D. Wrlson, Surgeon.

Eccleston-square, Nov. 13, 1843 .

on

THE MAJOR PERIODS

of

DEVELOPMENT IN MAN, BEING A SIXTH CONTRIBUTION TO PROLEPTICS.

By T. Laycock, M.D., Physician to the York Dispensary, \&c.

THE course of human life has been divided into periods from a very remote antiquity. The most casual observer must see that there is a progressive evolution of each individual, through infancy, youth, and puberty, to the climax of complete development, both mental and corporeal; and from thence a gradual involution of the system, and a decline of all the powers, until the man descends into what has been expressively termed his second childhood, and, at last, into the grave. This cycle of change, looked at as a whole, gives to the mind the idea of ascent and descent,-not quickly or irregularly, but step by step; and since certain points are well marked in the course of life (as dentition, puberty, the decline of the sexual functions, \&c.), and divide it into distinct periods, these were termed by the Greeks, with reference to this idea, climacteric, from $\kappa \lambda i ́ \mu a \xi$, gradus, scala, a step, or series of steps. The modern German term for the climacteric years, siufenjahre, stepyears, expresses the same idea. These years and periods have also been termed septenary, from an early age, because the latter were supposed to comprise a lapse of seven years, so that the climacteric and septenary periods are synonymous. The origin of this idea of periods of seven years is lost in remote antiquity. It formed a part of the doctrines of Pygathoras, who, it appears, was not the founder, but only the European propagator of these doctrines, he having derived them from the ancient Egyptians or Chaldeans. As applied by the latter, they referred not only to the health, but to the events of a man's life. "Pericula quoque vitæ fortunarumque hominum quæ climacteras Chaldæi appellant, gravissima quæque fieri affirmat Aristides Samius septenariis."' (Aulus Gellius, lib. iii., cap. x.) This doctrine of septenniads and septenaries has come down to modern times almost unchanged. Its history presents the singular phenomenon of a mere philosophical dogma passing uninjured through the most extensive revolutions in human society, and surviving the utter overthrow of empires and religions. Long after the age of Pygathoras we trace it in the Hippocratic writings; it is prominent in those of the later Greeks; it flourished in the middle ages; and it is extensively adopted by modern physicians. The editor of the "Medico-Chirurgical Review," for example, divides life into ten septenniads, after the ancient mode, asserting, further, that there is a difference of seven years between the two sexes, not in the actual duration of life, but in the stamina of the constitution, the symmetry of the form, and the lineaments of the face. (Economy of Health, second edition, p. 66.) It is manifest that the major vital periods can only be marked by changes in structure or function. By the observation of these changes the ancients professed to subdivide the whole period of life; and this plan, indeed, is the only safe plan for the modern scientific inquirer. He must observe the evolution of structure, of function, and of disease.

Diocles, the successor of Hippocrates both in fame and skill, wrote a book " concerning weeks." Macrobius has a notice of his doctrines, which describe the develop 
ment of the individual man as follows:The limbs of the male foetus are distinct at the seventh week and the birth takes place at the ninth month, but if they be distinct at the fifth week, birth takes place at the seventh month. If the infant survive the seventh hour, it will probably live; at the end of seven days the umbilical cord sloughs off; in $2 \times 7$ days the infant perceives the light, and in $7 \times 7$ days it turns its head to follow with its eyes the objects presented to it. When seven months old, its teeth begin to develop; in $2 \times 7$ months it can sit without fear of falling; after $3 \times 7$ months it speaks; in $4 \times 7$ months it is sufficiently strong to walk firmly; and at $5 \times 7$ months it has an aversion for the breast. At the age of seven years it loses its first teeth and speaks distinctly; at $2 \times 7$ years it attains the age of puberty; at $3 \times 7$ the beard appears and the youth ceases to grow in height; and at $4 \times 7$ be ceases to increase in size. In $5 \times 7$ years the man is at his full strength, and so continues at $6 \times 7$; but at $7 \times 7$ the strength somewhat diminisbes. Lastly, at $10 \times 7$ (the two most perfect numbers) are the limits of life, and those who have passed this term are exempt from all labour. (Le Clerc, Histoire de la Médecine, p. 281.) "The days of our years are three-score years and ten." So wrote Moses, a philosopher, poet, historian, and statesman, the supposed fellow-student of Hermes in the college of ( in, and undoubtedly a man learned in all the learning of the Egyptians; and he adds, almost immediately, "so teach us to number" our days that we may apply our hearts unto wisdom," as if he had been pondering over the philosophy then current, and thinking how stoically it calculated the duration of the health and life of man, numbered his days, and hopelessly demonstrated their termination.

The doctrines of Dincles are distinctly laid down in the Hippocratic writings, especially in the book entitled "De Carnibus," and in those "De Septimestri Partu" and "De Octimestri Partu," written apparently by the same author. The writer refers to the septennial phases, and specially notes the teeth developed in the fourth septenary, which he terms moderatores. That the life of man is circumscribed by the number of seven days is manifest, he observes, and then refers, like Diocles, to the periods of fcetal development, but introduces decades of ueeks, and observes that the period of uterogestation is four decades of weeks. He also states the doctrine of equal and unequal days; connects the periods of fevers with the periods of development; and refers to the full moon as having influence.

Some critics have remarked that the book

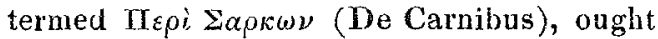
to be entitled II $\varepsilon \rho i$ 'A $\rho \chi \omega \nu$ De Principis, concerning principles. It is very probable that this and the two following books consti- tute an exposition of the Pygathorean doctrines as they were applied to transcendental physiology and medicine when the author wrote.* Hippocrates was thoroughly im. bued with these views, and has left several practical observations. For example, he says that convulsions do not accompany fever in patients above the age of seven years, and that if they do, they indicate danger. According to him, the following diseases do not attack individuals under the age of puberty, or fourteen years :-infam. mations of the lungs, pains in the side, gout, diseases of the kidneys, varicose veins of the legs, menorrhagia, cancer, a species of leprosy (vitiligo), a disease termed dellexion on the medulla spinalis, hæmorrhoids, and a disease of the intestines termed chordapsos. From the fourteenth to the forty-second year, any kind of disease may attack the system, but from the latter to the sixty-third it is exempt from struma, from calculus in the bladder (unless it existed previously), from defluxion on the spinal medulla, from diseases of the kidneys, unless arising in previous years, from bleeding piles, and from menorrhagia, except when connected with antecedent disease. These statements, whether considered physiologically or pathologically, are correct upon the whole.

The preceding remarks must serve as an exposition of the doctrines of the ancients regarding septenaries. It now remains to inquire how far these doctrines are true, and what practical benefits can be derived from them.

In man, life may be divided into three great periods. The first may be defined as extending from the commencement of intrauterine existence to the complete evolution of the sexual organs; the second comprises the period in which those organs are active; and the third extends from the period when they cease to act to the termination of life. These are clear and well-defined epochs, but it is difficult to fix their precise dates, for all vital changes are gradual, and do not admit of exact limitation. Similar difficulty is experienced in the attempt at a natural classification of animals, and is only overcome by having transition or inosculant groups. We may adopt a like expedient here. The first period may be stated as comprising 21 years, the second 28 years, and the third 21 years. The secondary periods of the

* Burdach, the German physiologist, adopts the decade numeration in a work he has published on the periods of life, entitled "Die Zeitrechnung des Menschlichen Le. bens ;" Leipzig, 1829. According to M. Quetelet (for 1 have not seen the book) he divides life into ten periods of four hundred weeks each, and thus makes an age of the first dentition, adolescence, \&c. In the first period is a secondary one of forty weeks, the age of lactation. 
first great period will be seven, namely,1 , intra-uterine life; 2 , the period between birth and the first dentition; 3 , the time occupied by the first dentition; 4 , the period between the first and second dentitions; 5 , the time of the second dentition; 6 , the period between the latter and commencing puberty; 7 , the time occupied in the evolution of the reproductive organs. The second great period will comprise three minor periods. First, the perfecting of adolescence from 21 to 28 ; secondly, the climax of development, or status of life, from 21 to 42 ; and thirdly, the septenary of decline in the reproductive powers, extending firom $\$ 2$ to 49 , after which latter age conception rarely takes place. The third comprises also three periods, the first from 49 to 63 , the grand climacteric; the second from 63 to 70 , or old age; and the third from 70 to death, the years of atas ingravescens, or decrepitude. In fixing these epochs I have followed the generally-received septennial division, being reluctant to make any innovation thereon. It would, I think, however, be more in accordance with modern science to date, not from the birth, but the conception of the individual. If this be done, each great period should be calculated as commencing nine solar months earlier.

Those of the readers of The Lancet who may have perused the first paper in my series would observe that the periods of development in insects were more particularly alluded to as establishing the minor periods, namely, those in relation with critical days, the catamenial period, \&c. These phases of development, in birds, are indicated in most instances by moulting, a process in which the mucous membrane of the whole system is implicated, as well as the skin and its appendages. In all birds a moult takes place sooner or later after being hatched, but it does not clearly appear what dentition (for this is analogous to moulting) corresponds to this moult. I am inclined to think, how. ever, that its analogue is neither the first nor the second dentition, but both. The plumage characteristic of the sexes begins to appear at this moult, and it is always a period of danger to domesticated birds, as peacocks, turkeys, pheasants, canaries, \&c. As iron is recommended for their cure, the state of health seems analogous to the chlo. rotic condition of young people. Buffon remarks that the period is analogous to dentition in children, meaning, I suppose, the first. In turkies it occurs in six or eight weeks after the hatch; in peacocks, four weeks ; in partridges, twelve weeks ; in canaries, five or six weeks. The period during which the eyes of some mammals are closed after birth is worthy notice, this being evidently heptal. In whelps it is fourteen days; in bear-cubs, twenty-eight days. It th may be possible that the idea of Diocles, respecting the first use of the eyes after birth, may have some foundation in truth. That some change takes place in the infant in the eighth week may be fairly inferred from the fact that the man with ichthyosis, (the porcupine man) whose history is detailed in an early volume of the "Philosophical Transactions" (1731), and who transmitted his disease to his progeny, stated that the cutaneous affection appeared in himself when about seven or eight weeks old; and we find, subsequently, that his six children had the disease tirst at the same age. The tusks of young elephants are shed in the twelfth or thirteenth year, but the cheekteeth appear six or seven weeks after birth. But the seventh and fourteenth days of infants seem to constitute periods. M. Quetelet finds that the weight of an infant diminishes sensibly immediately after birth, and does not begin to increase until after the seventh day. In 1S10, Dr. Holland published a table of deaths in newly-born infants from tetanus, in the Westmann islands, Iceland, and denoted the days most fatal : in 185 deaths, 75 took place on the seventh day. A few hours must be allowed for retarded labour and errors in computation, but if we take the sixth, seventh, and eighth days the average of deaths is $37 \frac{2}{3}$ daily, while the average of the remaining 18 days is only 4. An increased mortality took place' on the fourteenth day after birth. (Edin. Med and Surg. Jour., vol. viii., p. 207.) The fuurteenth day after birth is marked also by changes in the lower animals.

The order of development of the teeth in man is an interesting subject, as upon it we must principally rely for determining the periods of development in the system generally. Mr. Goodsir's researches are exceedingly interesting, as marking their gradual hebdomadal evolution in the embryo and foetus, but are not sufficiently accurate for our purpose as to the time when the changes occur. Previously to the eruptive stage, or common dentition, there are three phases of development: the papillary, commencing about the seventh week of foetal life, the follicular in the tenth, and the saccular in the fourteenth week, which continue until the eruptive stage, about the seventh month after birth, when the four central incisors present themselves. After this period the other teeth appear at intervals not yet precisely fixed, the first dentition being terminated, however, by the end of the thirtysixth month. All is then quiescent for three or four years, or until about the middle or end of the seventh year, when the first true molar makes its appearance, and which, according to Mr. Goodsir, is analogous to the milk-teeth in its mode of formation, the permanent central incisors appearing about the same time. Mr. Saunders has proposed to make use of the development of the permanent teeth to ascertain the ages of factory 
children, and his table, deduced from several hundreds of observations, is as follows:-

The first true molars appear at the age of ................ 7 years.

The central incisors $\ldots \ldots \ldots \ldots 8$

lateral incisors.......... 9

first bicuspids .......... 10

second bicuspid ..........11

canine ...............12 to 121

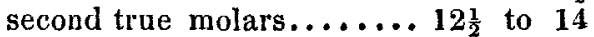

The third pair of molars, the dentes sapientia, appear later; according to Meckel and Goodsir, at from 16 to 20 years.

In animals generally the development of the teeth is closely connected with the evolution of the reproductive organs. The tusks of the stallion, wild boar, and walrus, are sexual, and are simply canine teeth of an unusual size. Upon inquiring how far the teeth are related to the reproductive organs in man, it is interesting to observe that there is occasionally a coincidence of development between the two, which, a priori, would seem improbable. From time to time instances of precocious puberty hava been recorded, and it would appear that the change in the ovaria or testes, and in the system generally, has occurred concurrently with a period of about forty weeks after birth, or with the first or second dentition. I have collected 17 instances of this kind, with the following results: -5 were males and 12 females; of these, 3 males and 1 female were more fully developed than usual at birth ; of the remaining, 1 male and 3 females exhibited the phenomena of incipient puberty at the age of eight or nine months, $l$ at two years, $I$ at two years and a half; 6 had the catamenia or were fully developed at three or four years, and 3 were perfect women at eight years. Two of the latter were pregnant at that age, and the remaining one lived to have a numerous family. In all these instances in which the growth of the teeth is alluded to, it is to state that it was irregular. (Vide Lond. Med. and Phys. Jour., vols. vii., xxiv., xxv., lxv; New Lond. Med. and Phys. Jour., vol. ii.; Med..Chir. Transactions, vol. i., ii., xii., \&c.)

It is probable, indeed, that sexual development takes place in these cases, as well as normally, per saltum, an effort being made just at the time when certain teeth are appearing ; after the tooth is perfected, and the constitutional effort has ceased, so also will the nisus in the ovaria or testes. Occasionally the catamenia appear in young females about the age of twelve or thirteen, for once or twice, when the canine teeth are protruding; and then cease, to re-appear only when puberty fairly commences, about the age of fourteen, the period at which the second molars burst forth. Taking the appearance of the teeth as indicating the periods of a constitutional nisus, we must look upon the third molar teeth as marking the commencement of that last stage of development in which the individual is perfected.

Upon a review of dental development it will be observed that the periods lengthen as age advances. First, the primary papillie appear hebdomadally in the foetal state; then, during the eruptive stage, the teeth succeed each other at intervals of six or eight weeks, but afterwards of three or four months. During the second dentition the interval is at first a year, then a year and a half, or two years, then four or five years, The dentition observed at an advanced age I shall notice subsequently.

What relations have these dental periods to function, disease, and death? First, as regards function. The development of the thorax in males, concurrently with the testes, alters the functions of the lungs; besides, as plants consume a larger quantity of oxygen while flowering, or, in other words, when at puberty, we may look for an increased consumption in animals and man at puberty. Now, M. Andral has found that the excretion of carbonic acid from the lungs is greater in males than in females after eight years of age ; in the former, at puberty, the quantity suddenly increases, while in the latter, when the catamenia commence, the excretion is as suddenly arrested, and rimains stationary in quantity, and almost as small as in childhood, so long as the monthly nisus continues: when this ceases, or when pregnancy takes place, the quantily immediately increases. In males the excretion begins to diminish in quantity at the age of 30 ; between 16 and that age it is double that excreted by the female. $M$. Bourgery made experiments on the capacity of the lungs in the two sexes at different ages. He found that the volume of the respiration of the male doubles that of the female, and that the plenitude in both sexe's occurs at the age of 30 . The volume of air required by an individual in an ordinary respiration augments gradually with the age. The relations between the ages of $7,15,20$, and 80 , are geometrical, and represented by the numbers 1, 2, 4, 8. (Dublin Medical Press, March 15, 1843.)

The muscular system acquires additional development during the second dentition, and in boys the respiratory movements are pro. portionalls active; but it appears that they are not so in girls, and we can thus explain the greater prevalence of chorea in the latter at sex the second dentition. The less liability to convulsions, on the access of febrile afiections, may be connected with this increased muscularity. According to Quetelet, during childhood the lumbar power of boys is about one-third more than that of girls; towards the age of puberty one-half; and the strength of a developed man is double that of a woman. These data correspond so closely 
with those of Bourgery and Andral, on the respiratory functions, that the coincidence cannot be casual.

M. Quetelet also shows that the ratio of growth of a child in height diminishes as its age increases, until the end of the first dentition. From the fourth or fifth year the increase of stature is almost the same in each year up to the sixteenth, when it diminishes gradually until the attainment of the 25th year, if a male, but earlier if a female. The weight follows the same rate of increase as the height.

Accolding to Quetelet the viability between birth and complete puberty varies considerably at different ages. From birth to the completion of the first dentition the mortality is great; it then diminishes, and at the age of five years the probability of life attains its maximum. At 13 or 14 a favourable change is again observed; riability is then at its maximum, or, in other words, it is the period when man can most depend upon his actual existence. The periods of dentition (and also the analogous periods of moult in animals) are the times when the individual is most liable to disease, and, during the first dentition at least, to death. Mr. Farr's tables show this very strikingly. The eruption of each individual tooth, both in the first and second dentition, is invariably attended with considerable constitutional disturbance in delicate persons, so considerable, indeed, during even the eruption of the third molars, or dentes sapientia, as sometimes to create alarm. The great mortality in the first four months of infantile existence seems to be connected rather with congenital debility, many only breathing once or twice ; or with extraneous circumstances, as early exposure to cold, 8c. Antecedently to the first dentition infants are remarkably free from the attacks of prevalent and fatal epidemics.

The development of the reproductive organs has a secondary influence on the system at large, and modifies its diseases. In males (as just stated) the thoracic region is more fully developed, the respiration and circulation becoming more active. We can thus explain the liability of youths to diseases of the heart, and to hæmoptysis and other pulmonary affections. In both sexes the kidneys are acted upon by the ovaria and testes, and their functional activity is exalted or diminished. Hence a class of diseases is observed in youth analogous to those observed in spring and autumn. In females with the gouty diathesis this ovarian action upon the kidneys develops those irregular forms of hysteria which so often baffle the skill of the routinist. The irritation set up in various organs connected anatomically or physiologically with the ovaria, as, for example, the organs of voice, the mammæ, the pelvic viscera, the dorso-lumbar cord, and those parts of the encephalon associated with the sexual instinct, is so great as to simulate infammation, and being founded on an arthritic diathesis it assumes the mi. gratory character of arthritic disease. Thus the diagnosis and the treatment are rendered hopelessly difficult to the practitioner whose "practical" knowledge is not derived from the true source of practical skill, namely, a knowledge and just appreciation of physiological laws.

These views respecting the ovarian and renal origin of the anomalous forms of hysteria are developed at length in my published work; as they are based on the solid foundation of physiology applied to patho$\log y$, I venture to hope that in proportion as the solido-humoral pathology of the day is perfected, their correctness will be admitted. It is manifest that as the due evolution of the system in youth is necessary to healthy and useful manhood, and to a comfortable old age, the laws of development and their bearing on pathology are of the first importance.

To consider the remaining periods of life, namely, the status and decline, would be to review the whole domain of pathology. After the age of 30 or $\mathbf{3 5}$ the abdominal viscera play a more important part in health and disease, and often gire the latter its distinguishing characteristics. It is worthy of remark, that just as precocious puberty is occasionally seen in infancy, so an attempt at rejuvenescence is sometimes made in old age, about the grand climacteric, or later. There is a fresh eruption of teeth, a complete set sometimes protruding, the reproductive organs reassume their activity, and the catamenia again appear, as well as other phenomena, observed only during the evolution of the system. Stoll, Good, and others, have recorded instances of this kind. That this is not mere chance is shown by the fact that a similar change is observed in the lower animals. Gallinaceous albinos-pheasants, for example,-according to Temminck, will assume all their former brilliancy of plumage, proving (since the latter is strictly sexual) that the reproductive organs are again active. The hen of the gallinaceous and other birds occasionally approximates in plumage to the cock, and ceases laying. It has been shown by Yarrell that this change is connected with a shrinking of the ovaries; but sometimes the male plumage falls off, and that of the female is re-developed, and then the bird lays eggs again. Nature herself here exhibits something like perpetual youth, and those who wish for this grand desideratum would do well to inquire closely into the circumstances which accompany the rejuvenescence described.

The periods of life have a much more important and practical bearing on the periodic development of hereditary disease. It is as certainly true that all the peculiarities of the parent are transmitted to the offspring, as 
that the whole is equal to the sum of all its parts. Some or many of the peculiarities derived from the one parent may be negatived by peculiarities derived from the other, or even by extraneous circumstances, and not be manifest in the offspring; but they are not the less surely there, and may and do reappear in the third or fourth generation. In a previous paper I observed that as conception took place at a minor period (the catamenial), the minor periods, at least, of the offspring, would correspond to those of the mother, and that if twins dated their conception from the same hour, the periods of their life would be coincident. I gave, also, an illustration of this inference, in which twins (two boys) went through dentition, and were attacked by indisposition and infantile disease always at the same time. Stoll seems to have suspected some coincidences of this kind when he remarked - Utile est observare necne semper eo tempore quo infans corripitur epilepsia matri fluant meuses, necne." (Ratio Medendi, Aphor. 209.) What is true of the minor periods is true of the major, and examples in proof are numerous. Phthisis carries off the members of a family as they successively arrive at a certain stage of development; insanity appears at a known age in all the members of another; apoplexy and paralysis in those of a third, \&c. Dr. Martin has recorded a striking example of this periodic development of hereditary disease. A person named Moses Le Compte, who was blind, had thirty-seven children and grandchildren that became blind like himself. The blindness is described as commencing in all about the age of fifteen or sixteen, and terminating in total deprivation of sight about twenty-two. (Quoted from the Baltimore Med. and Phys. Repos., in New Lond. Med. and Phys. Jour., vol. i., p. 394.) But, indeed, many similar instances might be quoted from numerous writers, which, if less striking, are equally instructive. Such may be found, for example, in Dr. Holland's interesting essay on the Hereditaly Transmission of Diseases. (Vide Medical Notes and Reflections, p. 27, 1st edition.) The assiduous cultivation of this branch of vital proleptics pronises the most valuable and practical results. Every family should possess jts medical history, with exact dates, just as a nation its archives, and illustrated by a series of Daguerreotype portraits. The physician could then have data that might enable him to anticipate hereditary disease, and if not to"prevent its development, at least, to predict its occurreace and modify its influence. But, indeed, if the laws regulating the hereditary transmission and periodic evolution of morbid states be once clearly ascertained in all their relations, much of the imperfection of medical science would be obviated, and its value proportionally exalted.

\section{ABSTRACT OF A REPOR'T ON THE}

\section{DEVELOPMENT OF THE OVUM OF MAN AND THE MAMMIFERA.}

IN the "British and Foreign Medical Review," for October last, is an elaborate memoir upon the ova of man and certain mammiferous animals, before and after fecundation, by Mr. Wharton Jones, who has there brought into juxta-position nearly all the more important results obtained by the researches of Baer, Bischoff, Henle, Valentin, Martin Barry, Coste, Wagner, and many other authorities, together with his own inquiries on this very intricate subject. In nearly every successive step in the process of development of the ovum, the opinions as well as the facts recorded by the foregoing observers are there compared, and a judgment is pronounced between conflicting views,-a circumstance which gives to certain parts of the essay in question somewhat of a controversial character. Divesting it, however, of all its polemical matter, and of most of the statements on which a difference of opinion exists between the higher authorities upon the subject, the following will be found to be a brief summary of the contents of Mr. Jones's Report of the leading facts which, according to him, have been established concerning the development of the ovum in certain mammifera, from the time at which it leaves the ovary, to its reception, and the early period of fotal development, in the uterus.

The Graafian follicles in the ovary are lined by a membraniform layer of nucleated cells, one two-thousandth of an inch in diameter, termed, by Baer, the membrana grumulosa. At its surface this membrane is thicker than elsewhere, presenting there a greater number of cells, which was (wrongly) named, by Baer," "discus proligerus." In its central part the ovum may be seen as an opake white speck, when the wall of the follicle is transparent.

Ovum and Yelk.-The granular mass in the centre of the ovum is almost uniformly recognised as analogous to the yelk of the bird's egg; and the broad transparent ring, or zona pellucida, which surrounds it, is al. lowed to be " the optical expression of the circumferential doubling of a thick transparent membrane which encloses the yelk." The yelk is composed of granules, the larger about one five-thousandth of an inch in diameter, and resembling fat or milk-globules, held together by a clear viscid substance, sometimes firmly, but at other times very 